EESTI NSV TEADUSTE AKADEEMIA TOIMETISED. XVI KOIDE

KEEMIA * GEOLOOGIA. 1967, NR. 1

ИЗВЕСТИЯ АКАДЕМИИ НАУК ЭСТОНСКОИ ССР. ТОМ ХVI

Химия * ГЕОЛОГИя. 1967, 치

А. ФОМИНА, Л. НАППА

\title{
О ПРОДУКТАХ ГИДРОЛИЗА КЕРОГЕНА КУКЕРСИТА Сообщение второе
}

$\mathrm{K}$ настоящему времени вопрос об участин углеводов и их прсизводных в образовании гумуса почв и твердых горючих ископаемых уже не вызывает сомнений. Обширные сведения по этой проблеме приведены в монографиях М. Кононовой [1] и С. Манской и Т. Дроздовой $\left[{ }^{2}\right]$.

K. Эндерс [3] считал, что углеводы разлагаются бактериями до метилглиоксаля и затем пронсходит конденсация его с аминокислотами, в результате чего образуются гуминовые кислоты разной степени сложности.

По данным В. Кретовича с соазторами [4], образование гуминовых кислот «Майяра» или меланоидинов [5] из углеводов и азотсодержащих веществ представляет собой сложный окислительно-восстановительный процесс.

$\mathrm{X}$. Тиле и X. Кеттнер [б считают, что гуминовые кислоты с основным ароматическим ядром легко образуются из полимерных углеводов н полиуроновых кислот путем отщепления от них воды.

Углеводы, даже целлюлоза, обнаружены в лигнитах Н. Караваевым [7]. Работами В. Раковского и сотрудников [8] установлено, что из торфообразователей, содержащих мало лигнина, но много углеводов, образуются гуминовые кислоты с высоким выходом.

Однако в углехимической литературе не упоминается о возможности участия в образовании твердых горючих ископаемых таких производных углеводов, как сложные эфиры углеводов и жирных кислот, которые тем не менее существуют в природе, в частности в микробном мире. Известно, что в образовании твердых горючих ископаемых значительную роль играют бактерии, перерабатывающие отмеріий животный и растительный материал. В некоторых случаях масса бактерий достигает 6-7\% от общего количества ила [?]. Отсутствие данных о липоуглеводах, по-видимому, объясняется тем, что они до настоящего времени являются наименее изученными [10]. Некоторое представление об этих веществах можно получить по данным Е. Алимовой [1'] (табл. 1). Как указывают авторы [19], липазы не оказывают расщепляющего действия на липоуглеводы.

Из приведенных данных следует, что углеводы флоры и микробного мира могут участвовать в образовании твердых горючих ископаемых, в том. числе и керогенов горючих сланцев, в виде различных сложных веществ.

Как уже указывалось в кратком сообщении [12], на хроматограмме гидролизата керогена кукерсита были установлены некоторые простые сахара. Это указывало на целесообразность более детального анализа гидролизатов. С этой целью было проведено две серии ступенчатых опытов гидролиза керогена $5 \%$-ной соляной кислотой на кипящей водянод̆ бане при длительности одной ступени 2 \%. Сырьем служил кон- 
Характеристика липоуглеводов, выделенных из патогенных бактерий [11]

\begin{tabular}{|c|c|c|c|}
\hline \multirow{2}{*}{$\begin{array}{l}\text { Фракция } \\
\text { экстрак- } \\
\text { тов }\end{array}$} & \multirow[b]{2}{*}{ Внешний вид } & \multicolumn{2}{|c|}{ Продукты омыления } \\
\hline & & $\begin{array}{l}\text { Водораствори- } \\
\text { мые вещества }\end{array}$ & Жирные кислоты \\
\hline B & $\begin{array}{l}\text { Твердое вещество светло- } \\
\text { коричневого цвета }\end{array}$ & Трегалоза * & $\begin{array}{lllll}\text { Твердые: } & \mathrm{C}_{30}, & \mathrm{C}_{26}, & \mathrm{C}_{24}, & \mathrm{C}_{22}, \\
& \mathrm{C}_{16}, & \mathrm{C}_{14} & \\
\text { Жидкие: } & \mathrm{C}_{30}, & \mathrm{C}_{28}, & \mathrm{C}_{22}, & \mathrm{C}_{20}, \\
& \mathrm{C}_{18}, & \mathrm{C}_{16} & \\
\end{array}$ \\
\hline$\Gamma$ & Порошок бесцветный & Трегалоза * & $\begin{array}{l}\text { Твердые: } \mathrm{C}_{26}, \mathrm{C}_{22}, \mathrm{C}_{16}, \mathrm{C}_{14} \\
\text { Жидкие: } \mathrm{C}_{22}, \mathrm{C}_{20}\end{array}$ \\
\hline A & Порошок бесіветный & $\begin{array}{l}\text { Полисахари- } \\
\text { ды (манноза, } \\
\text { галактоза, ара- } \\
\text { бнноза) }\end{array}$ & $\mathrm{C}_{24}, \mathrm{C}_{22}, \mathrm{C}_{20}, \mathrm{C}_{18}, \mathrm{C}_{16}, \mathrm{C}_{14}$ \\
\hline
\end{tabular}

* Глюкозидо-глюкозид.

** Продукты гидролиза.

центрат флотационного обогащения сланца, приготовленный в секторе обогатительных процессов нашего института. Метод очистки концентрата от примесей флотореагента и остаточных карбонатов, а также элементарный состав керогена после вышеуказанных обработок описаны в [12].

Чтобы избавиться от сомнений в происхождении сахаров, гидролизат первой ступени отбрасывался. В первой серии опытов (945 а керогена) было проведено 11 ступеней гидролиза (10 рабочих растворов); во второй серии (240 г керогена) - 26 ступеней гидролиза (25 рабочих растворов) при атмосферном давлении и суммарном времени 52 ; остаток гидролизовался в течение 3 в в автоклаве при $130^{\circ} \mathrm{C}$.

Гидролизаты каждой ступени обеих серий опытов выпаривались в вакууме при температуре не выше $40^{\circ}$. Затем они очищались пропусканием через колонку с ионообменником КУ-2 в Н-форме. Углеводы из колонки выходят вместе с водой; если же гидролизат содержит аминокислоты, то они задерживаются на смоле и затем элюируются 2 н. водным раствором аммиака. Водные растворы и аммиачные элюаты выпаривались в вакууме досуха при температуре не выше $40^{\circ}$. Остатки, полученные от отдельных ступеней гидролиза, соединялись для каждой серии отдельно. После очистки на катионите гидролизат сахаров еще содержал остатки соляной кислоты, которая мешала их четкому разделению при хроматографии на бумаге. Для удаления остатков соляной кислоты к водному раствору сахаров добавляли порошок углекислого серебра. Образовавшийся осадок хлористого серебра отфильтровывали через плотный фильтр и промывали до отрицательной реакции на углеводы (проба с 80\%-ным водным раствором фенола и концентрированной серной кислоты). Для удаления ионов серебра раствор пропускался через колонку с катионитом «Зеролит» 225 SRC-13 крупностью 14-25 меш.

Элюат, полученный после этой очистки, выпаривали до вязкого остатка. После этого пробу остатка подвергали анализу. Для этого соответствующее количество гидролизата наносили на ватманскую бумагу № 1 (для хроматографирования). Анализ проводили способом одномерной нисходящей хроматографии. Для разделения углеводов использовали смесь растворителей: пиридин - этилацетат - вода $(2: 8: 1)\left[{ }^{13}\right]$. 
Разделение производили в течение 16 ч. Проявителем служил анилин-о-фталат в растворе этилового спирта. Качественно из гидролизата идентифицированы арабиноза, ксилоза, глюкоза, галактоза и следы рамнозы. Для количественного определения сахаров в гидролизате на хроматографическую бумагу, кроме исследуемого гидролизата, наносились метчики - растворы индивидуальных сахаров известных концентраций.

После проявления хроматограммы полосы с пятнами сахаров вырезали для определения количественного содержания их в смеси. Oпределение пронзводили на фотометре фирмы Б. Ланге. Аппарат снабжен самопишущим устройством, регистрирующим количество каждого углевода в виде пиков, величина которых определялась концентрацией сахара на бумаге.

По площади пиков сахаров с известной концентрацией вычерчивались графики. По этим графикам и результатам, полученным для исследуемых сахаров, высчитывали их процентные и молярные соотношения в гидролизате. Результаты анализа приведены в табл. 2.

Таблица 2

Результаты анализов гидролизата керогена кукерсита на содержание углеводов и их соотношения в смеси

\begin{tabular}{|c|c|c|c|c|c|c|c|c|}
\hline \multirow[b]{2}{*}{ Происхождение гидролизата } & \multicolumn{2}{|c|}{ Ксилоза } & \multicolumn{2}{|c|}{ Глюкоза } & \multicolumn{2}{|c|}{ Арабиноза } & \multicolumn{2}{|c|}{ Галактоза } \\
\hline & $\%$ & молей & $\%$ & молей & $\%$ & молей & $\%$ & молей \\
\hline $\begin{array}{l}\text { 1. После } 11 \text { ступеней гидро- } \\
\text { лиза по } 2 \text { н на водяной бане } \\
2 \text {. Гіосле } 26 \text { ступеней гидро- } \\
\text { лиза на нодяной бане и } 3 \text { и } \\
\text { в автоклаве при } 130^{\circ}\end{array}$ & 10,6 & 1,0 & 25,2 & 2,8 & 33,3 & 3,7 & 32,5 & 3,6 \\
\hline
\end{tabular}

Из приведенных данных следует, что качественный анализ гидролизата керогена кукерсита позволил идентифицировать в нем пять простых углеводов. Однако содержание рамнозы было настолько мало, что использованный метод количественного анализа не показал ее. Как в гидролизате первой серии (10 ступеней), так и второй серии (25 ступеней) вместе с автоклавным гидролизом превалирующим компонентом в смеси сахаров является галактоза, за ней следуют арабиноза и глюкоза; меньше всего в смеси оказалось ксилозы. Наличия уроновых кислот в тидролизатах пока установить не удалось. Не удалось установить, в ччастности, и галактуроновую кислоту, являющуюся основным компонентом продуктов гидролиза пектиновых веществ. В то же время галактоза и арабиноза представляют собой элементарные звенья сопутствующих пектиновым веществам галактанов и арабанов. Идентифицированные сахара, например галактоза, арабиноза и ксилоза, являются также звеньями аморфных полисахаридов зеленых водорослей, основной скелет которых состоит из галактозы и арабинозы, а ксилоза наряду с галактозой представляет концевые группы. Все четыре сахара входят также в состав углеводных соединений сине-зеленых водорослей $\left[{ }^{14}\right]$.

M. Рогерс $\left[{ }^{15}\right]$ установил, что в водной растительности озер центральной части штата Миннесота (с $\mathrm{pH}$ среды выше 7) преобладающими простыми сахарами углеводной составляющей являются глюкоза, галактоза, ксилоза и арабиноза. Причиной стабилизации сахаров в осадке он считает микроорганизмы. В качестве стабильных углеводов в среде обследованных озер он называет ксилозу, глюкозу, рамнозу, арабинозу; 
менее устойчивых - рибозу, маннозу и галактозу и очень неустойчивой - глюкуроновую кислоту. Несомненно, сахара могут быть продуктами обмена и ресинтеза, например, такого типа ассимилирующих углеводы микроорганизмов, как миксобактерии [ $\left.{ }^{16}\right]$.

Можно считать установленным, что в макромолекулярном веществе керогена кукерсита имеются структурные элементы углеводной природы, часть которых сохранила способность гидролизоваться до простых сахаров. На данной стадии исследований еще нельзя считать, что проведен исчерпывающий гидролиз и что установлены все выделяюшиеся при этом сахара и их производные. Однако следует отмегить, что гидролиз и отщепление простых сахаров протекают постепенно, интенсифицируясь при гидролизе под давлением. Это может служить основанием для заключения о том, что структурные элементы углеводной природы, способные гидролизоваться, не являются концевыми группами основной структуры керогена, а находятся в более тесной взаимосвязи с другими составляющими макромолекул керогена, и поэтому проникновение к ним соляной кислоты (гетерогенная среда-твердая фаза-кероген и водный раствор соляной кислоты) происходит только по мере появления доступа к этим участкам сшитой структуры полимера.

Качественные реакции на азотсодержащие соединения во фракциях гидролизата, элюирующихся с катионита КУ-2 2 н. аммиачным раствором, дали положительные результаты. Это послужило основанием для проведения анализа побочного продукта, полученного в ходе основного исследования. Ход и результаты этой части работы излагаются ниже.

Элюат после тщательного выпаривания для удаления аммиака подвергался качественному и количественному анализам на автоматическом аминокислотном анализаторе чехословацкого производства , где разделение аминокислот происходит на ионообменных колонках по методике, описанной в [17]. Колонки заполняются ионитом амберлит ИР-120. Разделение аминокислот происходит на двух колонках: на малой колонке высотой $15 \mathrm{~cm}$ разделяются основные аминокислоты и на большой (высотой 150 см. - все другие аминокислоты. Разделение на малой колонке происходит в течение 8 и на большой - 22 ч. Анализатор снабжен самопишущим устройством. связанным с фотоэлементами. Проба гидролизата растворяется в цитратном буфере с $\mathrm{pH} 2,2$. $\mathrm{Ha}$ малой колонке элюирование аминокислот производится ацетатным буферным раствором с рН 5,28, на большой - c pH 4,25.

Результаты анализа первой серии ступенчатого гидролиза (10 ступе-

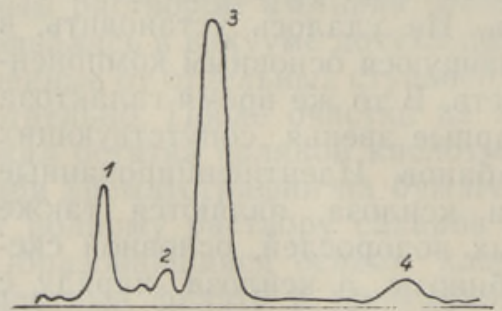

Рис. 1. Разделенне основных аминокислот из гидрслизата 10 ступеней на малой колонке: 1 - гистиднн: 2 - лизин; 3 - аммиак; 4 - аргинин, ней) приведены на рис. 1 и 2. Как следует из рис. 1 , из основных аминокислот в гидролизате идентифицированы гистидин, лизин и аргинин; на большой колонке (рис. 2) - аспарагиновая кислота, треонин, серин, глутаминовая кислота, пролин, глицин, аланин, цистеин и продукт его окисления - цистин, валин и серия неидентифицированных соединений (слитые пики). В гидролизате 25 -ступенчатого опыта с завершаюшим автоклавным гидролизом при $130^{\circ}$ были дополнительно идентифицированы лейцин, изолейцин, тирозин и фенилаланин. Последние относятся к неидентифицирован-

* Анализ проведен инженером Ц. Копецем в Институте химни Словацкой Академин наук в г. Братнславе. 


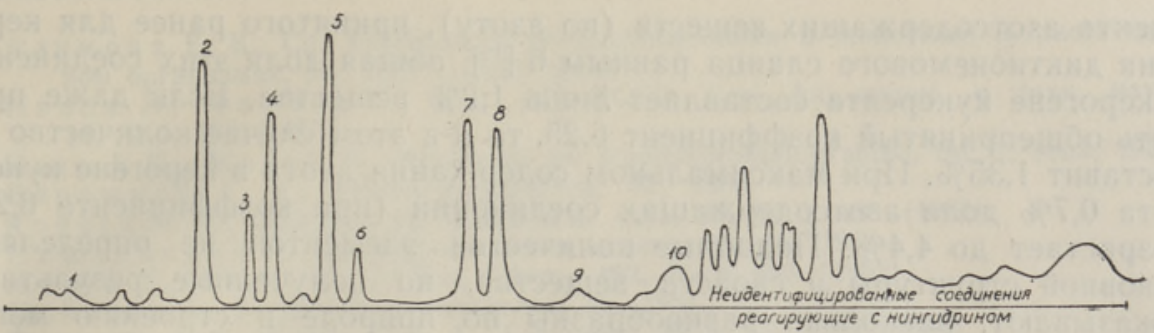

Рис. 2. Разделение аминокислот из гидролизата 10 ступеней на большой колонке:

1 - цистенн; 2 - аспарагнновая кислота; 3 - треонин; 4 - сернн; 5 - глутаминовая кнслота; 6 - пролин; 7 - глицин; 8 - аланин; 9 - цистин; 10 - валнн.

ной области пиков рис. 2. Неидентифицированная область пиков рис. 2 , по-видимому, относится к неполностью гидролизованным веществам ди-, три- и более сложным пептидам. Известно, что полипептиды, содержащие лейцин, тирозин и фенилаланин, трудно поддаются гидролизу. Из полученных хроматограмм следует, что преобладающими в смеси являются глутаминовая и аспарагиновая кислоты, за ними в убываюшем порядке следуют глицин, аланин, серин, гистидин, треонин и другие, в том числе весьма малые пики соответствуют тирозину и фенилаланину,

Несмотря на низкое содержание общего азота в керогене (в исследуемой пробе $0,2 \%$ ), азотсодержащие соединения его способны гидролизоваться до всех рядов аминокислот по А. Майстеру $\left[{ }^{18}\right]$. Так, были шдентифицированы:

Алифатические аминокислоты

Монокарбоновые:

глицин $\mathrm{NH}_{2} \cdot \mathrm{CH}_{2} \cdot \mathrm{COOH}$

аланин $\mathrm{CH}_{3} \cdot \mathrm{CH}\left(\mathrm{NH}_{2}\right) \cdot \mathrm{COOH}$

изолейщнн

$\mathrm{CH}_{3} \cdot \mathrm{CH}_{2} \cdot \mathrm{CH}\left(\mathrm{CH}_{3}\right) \cdot \mathrm{CH}\left(\mathrm{NH}_{2}\right) \cdot \mathrm{COOH}$

лейцин $\left(\mathrm{CH}_{3}\right)_{2} \cdot \mathrm{CH} \cdot \mathrm{CH}_{2} \mathrm{CH}\left(\mathrm{NH}_{2}\right) \cdot \mathrm{COOH}$ валин $\left(\mathrm{CH}_{3}\right)_{2} \cdot \mathrm{CH}\left(\mathrm{NH}_{2}\right) \cdot \mathrm{COOH}$

Оксимоноаминокарбоновые кислоты: серин $\mathrm{CH}_{2}(\mathrm{OH}) \mathrm{CH}\left(\mathrm{NH}_{2}\right) \cdot \mathrm{COOH}$ треонин $\mathrm{CH}_{3} \cdot \mathrm{CH}(\mathrm{OH}) \cdot \mathrm{CH}\left(\mathrm{NH}_{2}\right) \cdot \mathrm{COOH}$

Монсаминодикарбоновые кислоты: аспарагиновая $\mathrm{HOOC} \cdot \mathrm{CH}_{2} \cdot \mathrm{CH}\left(\mathrm{NH}_{2}\right) \cdot \mathrm{COOH}$

\author{
глутаминовая \\ $\mathrm{HOOC} \cdot \mathrm{CH}_{2} \cdot \mathrm{CH}_{2} \cdot \mathrm{CH}\left(\mathrm{NH}_{2}\right) \mathrm{COOH}$
}

Диаминомонокарбоновые кислоты: арганнн

$\mathrm{NH}=\mathrm{CNHCH}_{2} \cdot \mathrm{CH}_{2} \cdot \mathrm{CH}_{2} \cdot \mathrm{CH}\left(\mathrm{NH}_{2}\right) \cdot \mathrm{COOH}$ $\mathrm{NH}_{2}$

лизин

$\mathrm{CH}_{2}\left(\mathrm{NH}_{2}\right) \cdot \mathrm{CH}_{2} \cdot \mathrm{CH}_{2} \cdot \mathrm{CH}_{2} \cdot \mathrm{CH}\left(\mathrm{NH}_{2}\right) \cdot \mathrm{COOH}$

Серусодержащие аминокислоты: цистеин $\mathrm{HS} \cdot \mathrm{CH}_{2} \cdot \mathrm{CH}\left(\mathrm{NH}_{2}\right) \cdot \mathrm{COOH}$ цистин $\left[\mathrm{SCH}_{2} \mathrm{CH} \cdot\left(\mathrm{NH}_{2}\right) \cdot \mathrm{COOH}\right]_{2}$

А роматические а минокислоты: фенилаланин $\mathrm{C}_{6} \mathrm{H}_{5} \cdot \mathrm{CH}_{2} \cdot \mathrm{CH}\left(\mathrm{NH}_{2}\right) \cdot \mathrm{COOH}$ тирозин $\mathrm{HO} \cdot \mathrm{C}_{6} \mathrm{H}_{4} \cdot \mathrm{CH}_{2} \cdot \mathrm{CH}\left(\mathrm{NH}_{2}\right) \cdot \mathrm{COOH}$ Гетероциклические аминокислоты:

гистидин $\mathrm{HC}=\mathrm{C}-\mathrm{CH}_{2} \cdot \mathrm{CH}\left(\mathrm{NH}_{2}\right) \mathrm{COOH}$<smiles>C#N</smiles>

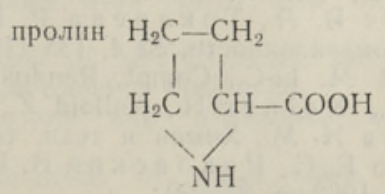

Таким образом, из гидролизата керогена кукерсита идентифицировано 17 аминокислот из 21, обычно встречающихся в белках [18]. Исходя из содержания общего азота в керогене $(0,2 \%)$ и среднего коэффи- 
циента азотсодержащих веществ (по азоту), принятого ранее для керогена диктионемового сланца равным $6\left[{ }^{19}\right]$, общая доля этих соединений в керогене кукерсита составляет лишь 1,2\% вещества. Если даже принять общепринятый коэффициент 6,25 , то и в этом случае количество их составит $1,35 \%$. При максимальном содержании азота в керогене кукерсита $0,7 \%$ доля азотсодержащих соединений (при коэффициенте 6,25) возрастает до $4,4 \%$. Подобные количества элементов не определяют основной структуры и свойств вещества, но полученные результаты показывают, насколько разнообразны по природе и строению могут быть составляющие макромолекул керогена. Идентифицированные аминокислоты, по-видимому, бактериального происхождения.

Заключая обсуждение экспериментальных данных, можно отметить, что в результате поискового исследования, проведенного с целью выяснения участия в составе керогена кукерсита структурных элементов углеводной природы, получены первичные данные, отвечающие на этот вопрос положительно.

После специальной подготовки керогена (с целью удаления возможных случайных примесей) последовательной обработкой его спирто-бензолом, спиртом, $5 \%$-ной соляной кислотой на холоду и $5 \%$-ной соляной кислотой на кипящей водяной бане в течение 2 и последующий ступенчатый гидролиз на кипящей водяной бане при атмосферном давлении, завершенный в автоклаве при $130^{\circ}$, позволил получить гидролизаты, содержащие простые сахара. Идентифицированные углеводы встречаются в полисахаридах водорослей, характерны они также для сопутствующих пектиновым веществам галактанам и арабанам, но могли быть и составляющими бактериального происхождения. Широкий «спектр» аминокислотной части гидролизата (идентифицировано 17 аминокислот) при весьма низком содержании общего азота наводит на мысль, что аминокислоты, по-видимому, бактериального происхождения.

Полученный фактический материал является основанием для постановки более углубленных исследований, так как вопрос об участии вецеств углеводной природы в образовании твердых горючих ископаемых хотя уже и не может отрицаться, но еще находится в стадии гипотез как о путях участия углеводов в образовании ископаемой органической материи, так и о последующих их превращениях, а также формах нахождения их в различных типах горючих ископаемых.

Авторы выражают глубокую благодарность доктору Р. Кону, инженеру Ц. Копецу и другим сотрудникам Института химии Словацкой Академии наук за помощь, оказанную в проведении анализов гидролизатов керогена кукерсита.

\section{Л И ТЕРА Т У Р А}

1. Кононов а М. М., Органическое вещество почвы, М., 1963.

2. М ан ск а я С. М., Д̈ р озд в в а Т. В., Геохимия органического вещества, М., 1964.

3. Enders C., Chemie, 56, H. 41/42, 281 (1943).

4. Кретович В. Л., Токарева Р. Р. Пет рова И. С., Тр. НИН хлебопекарной промышленности, № 4, 135 (1951).

5. M a ill a r d M. L.-C., Compt. Rendus, 156, № 15, 1159 (1913).

6. Thiele H., Ketner H., Kolloid Z., 130, H. 3, 257 (1953).

7. Караваев Н. М., Химия и техн. топлива и масел, № 1, 13-22 (1957).

8. Л укошко Е. С., Р аков с и й В. Е., Сб. Химия и генезис торфа и сапропелей, Минск, 1962 , с. $23-29$.

9. Кузнеп о в С. И., Сб. Химия и генезис твердых горючих ископаемых, М., 1953, c. 386 .

10. Алимова Е. К., Аствацатурьян А. Т., Болгова Т. Д., Сб. Углеводы и углеводный обмен, М., 1962, с. 294-301. 
11. Алим в а Е. К., Сб. Углеводы и углеводный обмен в животном и растительном организмах, М., 1959 , с. $255-261$.

12. Н а п а Л., Фомин а А., Изв. АН ӘССР. Сер. физ.матем. и техн. наук, 14, № 1, 163 (1965).

13. $\mathrm{H}$ a is I. M., M a c e k K., Handbuch der Papierchromatographie, Bd. 1, Jena, 1958.

14. Б а р ашков Г. К., Химия водорослей, М., 1963.

15. Rogers M. A., Geochim. et Cosmochim. Acta, 29, № 3, 183 (1965).

16. И мше н ні к и й А. А., Микробиология целлюлозы, М., 1953.

17. Moore S., Ste in W., J. Biol. Chem., 192, № 2, 663 (1951).

18. М а й стер А., Бнохимня аминокислот, М., 1961.

19. Фомин а А. С., Н а п п а Л. А., Геохимия, № 2, 163-170 (1964).

Ннститут химии
Академии наук Эстонской ССР $\quad$ Поступила в редакцию
$28 / \mathrm{I}$
1966

A. FOMINA, L. NAPPA

KUKERSIIDI KEROGEENI HUDROLOUSIPRODUKTIDEST. II

Artiklis esitatakse esialgse otsingulise uurimise tulemusi põlevkivikerogeenis leiduvate süsivesikute struktuurielementide kohta

Kukersiidi kerogeeni hüdrolüüsimiseks, mis toimus $5 \%$-lise soolhappega vesivannil astmeliselt kestusega à 2 tundi, korraldati kaks katseseeriat. Esimeses seerias hüdrolüüsiti 11 astmes (10 töölahust), teises -26 astmes (25 töölahust) tavalisel rōhul, millele järgnes kolmetunnine hüdrolüüs autoklaavis.

Hüdrolüsaadid puhastati kationiidi KU-2 abil ja saadi kaks fraktsiooni. Veega elueerimisel saadud fraktsioon sisaldas süsivesikuid, $2 \mathrm{n} \mathrm{NH}_{4} \mathrm{OH}$-lahusega elueeritud fraktsioon - aminohappeid.

Peale süsivesikute identifitseerimist paberkromatograafilisel meetodil määrati nende suhteline sisaldus hüdrolüsaadis Lange fotomeetri abil (tabel 2). Süsivesikutest domineerisid galaktoos ja arabinoos, kuna ramnoosi leidus vaid jälgedena. Identifitseeritud süsivesikud on karakteersed veetaimestikule. Galaktoos ja arabinoos on pektiinainetes leiduvate galaktaanide ja arabaanide elementaar-koostisosi.

Hüdrolüsaatides identifitseeriti automaatsel aminohapete analüsaatoril (Tšehhoslovakkia päritolu) 17 aminohapet. Kerogeeni madal lämmastikusisaldus ei luba lämmastiku struktuurielemente lugeda tema pōhistruktuurielementide hulka.

Kõnesoleva töö tulemused on aluseks edasisele põhjalikumale uurimistööle, eriti süsivesikute osas.

A. FOMINA, L. NAPPA

\section{ON PRODUCTS PREPARED BY HYDROLYSIS OF OIL SHALE (KUKERSITE). II}

The results of a study of carbohydrate structural units of the kerogen of oil shale (kukersite) are discussed.

Two series of hydrolysis were carried out (stage hydrolysis with a duration of 2 hours per stage, with 5 per cent hydrochloric acid on a boiling water-bath).

In the first series an eleven-stage hydrolysis was carried out, in the second, we had a twenty-six-stage hydrolysis at normal pressure and after that a three-hour hydrolysis in an autoclave.

The hydrolysates were purified and separated on an ion exchange column filled with cation exchange resin $\mathrm{KU}-2$.

Two fractions were collected. Carbohydrates were eluted with water and amino acids with $2 \mathrm{n} \mathrm{NH}_{4} \mathrm{OH}$.

After the paper chromatographic separation of carbohydrates, the chromatograms were evaluated quantitatively on a Lange photometer (Table 2).

The dominant carbohydrates were galactose and arabinose, while rhamnose occurred only in traces.

The identified carbohydrates are characteristic of water flora. Galactose and arabinose are main structural units of araban and galactan, the main constituents of pectin.

17 amino acids were identified in the hydrolysates on an automatic amino acid analyser.

The results could serve as a basis for a further detailed investigation. 